\title{
Disability and quality of life in headache: where we are now and where we are heading
}

\author{
D. D'Amico • L. Grazzi · S. Usai • M. Leonardi • \\ A. Raggi
}

(C) Springer-Verlag Italia 2013

\begin{abstract}
Headache disorders determine relevant personal and societal burden, and thus the use of patient-reported outcome measures (PROMs) investigating the level of disability and health-related quality of life (HRQoL) have been increasingly used in headache research. The aim of this review was to address the status of research on disability and HRQoL, by addressing results from recently published clinical trials as well as in longitudinal observational studies on headache patients. PubMed has been searched for papers in which measures of HRQoL and/or disability were used as primary or secondary outcome on adult subjects with primary headache, and published in 2010-2012. Among the 70 records retrieved, 12 papers were selected for narrative synthesis. They included data on 2,621 patients with episodic migraine with and without aura, chronic daily headache, and/or chronic migraine with and without medication overuse. The selected trials investigated the efficacy of different pharmacological prophylaxis, of some surgical approaches, of education programmes and osteopathic manipulative treatment; two studies reported longitudinal observations of patients currently under treatment. Overall, the results of our review showed that headache frequency as well as HRQoL and disability were positively impacted by treatment interventions; positive outcomes were less evident in two studies, and similar results were found in the two
\end{abstract}

D. D’Amico $(\varangle) \cdot$ L. Grazzi · S. Usai

Headache Unit, Department of Clinical Neuroscience,

C. Besta Neurological Institute and Foundation,

Via Celoria, 11, 20133 Milan, Italy

e-mail: damico.d@istituto-besta.it

M. Leonardi · A. Raggi

Neurology, Public Health and Disability Unit,

C. Besta Neurological Institute and Foundation,

Milan, Italy observational studies. Our findings confirmed that the most commonly used PROMs, including disease-specific tools to assess disability and HRQoL and SF-36, are sensitive to the beneficial effects occurring over time in functioning and quality of life domains in headache patients. They also suggest that the personal and societal costs of headache disorders are likely to be reduced when headache patients receive appropriate treatments and when continuity of care is offered. In terms of future directions, we note that the systematic use of appropriate PROMs should be encouraged both in the clinical practice and in the research field, as they offer a valid option to assess the global effect of treatments on patient-perceived sense of well-being and quality of performance.

Keywords Headache - Patient-reported outcome measures (PROMs) - Disability $\cdot$ Health related quality of life $\cdot$ Review

\section{Introduction}

Headache disorders determine relevant reductions in functioning and in quality of life. Recent reviews have been mostly focused on migraine and chronic daily headache $(\mathrm{CDH})$. These reviews showed that migraine substantially impairs a person's functions in different activity domains during attacks and diminishes health-related quality of life (HRQoL) during and between attacks [1], determining difficulties in specific aspects such as vitality, social functioning, mental and physical health [2]. Similar results were found for $\mathrm{CDH}$, which generally causes higher levels of burden and disability as well as more evident HRQoL reduction than episodic migraine, particularly in patients with medication overuse [3, 4]. 
Given the relevance of the personal and social burden imposed by headache disorders, the use of patient-reported outcome measures (PROMs) investigating the level of disability and HRQoL have been increasingly used in headache research. Some generic and disease-specific instruments have been used as secondary outcome measures in several clinical trials evaluating the efficacy of both acute and prophylactic medications in headache patients [2-4].

Aim of this review was to address the status of research on disability and HRQoL, by addressing results from recently published clinical trials as well as in longitudinal observational studies on headache patients.

\section{Methods}

PubMed has been searched for papers published in 2010-2012 that systematically assessed disability and/or HRQoL in headache disorders. Selection criteria were the following: clinical trials or longitudinal observational papers in which measures of HRQoL and/or disability were used as primary or secondary outcome; studies on adult subjects. Papers were excluded if the primary focus of research was not on headache, if information on HRQoL and/or disability was analysed only with cross-sectional methods, if information was derived from population studies or cases studies.
To ensure quality and consistency of data, abstracts and $20 \%$ of selected full-texts were double checked. Full-texts were analysed for their content and research results are presented with a narrative approach.

\section{Results}

In total, 70 records were retrieved, and 12 papers were selected for narrative synthesis. The flow of papers' selection is shown in Fig. 1 : these papers provided data from 2,621 patients with different diagnoses, i.e. episodic migraine with and without aura, $\mathrm{CDH}$, andlor chronic migraine with and without medication overuse. Table 1 provides an overview of selected papers' features and of the main outcome.

There were one trial on onabotulium toxin A [5], three trials on prophylactic medications, one on levetiracetam [6] and two on $\beta$-blockers $[7,8]$. Four studies described a surgical approach: two were procedures for deactivation of trigger sites [9, 10], one approach was the occipital nerve stimulation [11], and one approach was bariatric surgery for obese patients patients comorbid migraine [12]. Two studies reported short-term longitudinal observations of patients currently under treatment for migraine who were prescribed tailored medications including both acute and prophylactic ones $[13,14]$. Two studies presented results of non-pharmacological treatments, the first was based on a
Fig. 1 Flowchart of paper selection

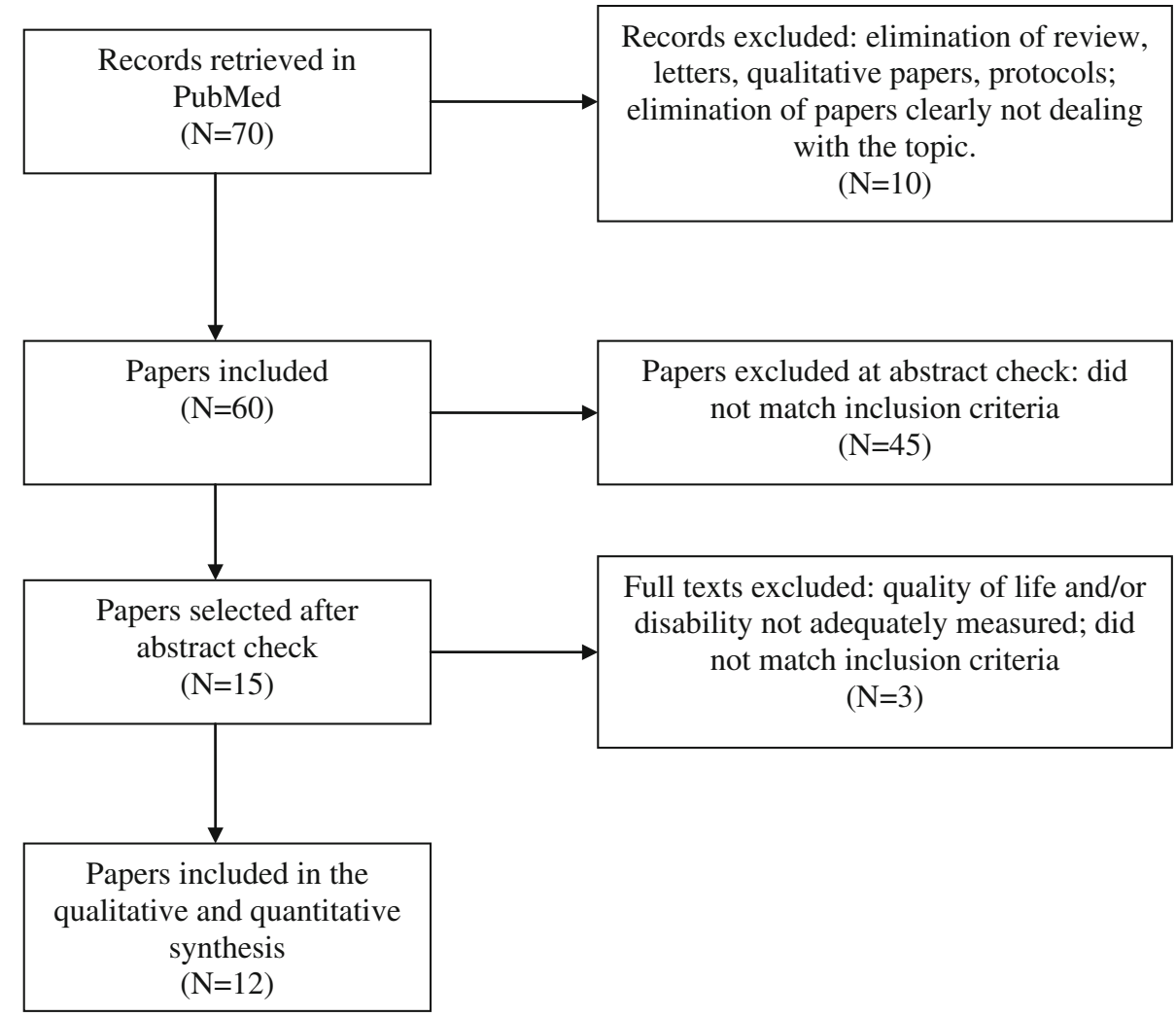


Table 1 Description of included papers

\begin{tabular}{|c|c|c|c|c|}
\hline References & $\begin{array}{l}\text { Sample } \\
\text { description }\end{array}$ & Intervention & $\begin{array}{l}\text { Outcome } \\
\text { measures }\end{array}$ & Results \\
\hline $\begin{array}{l}\text { Dodick } \\
\text { et al. [5] }\end{array}$ & $\begin{array}{l}1,384 \text { pts } \\
\text { with CM }\end{array}$ & $\begin{array}{l}\text { OnabotuniumtoxinA vs. } \\
\text { placebo }\end{array}$ & $\begin{array}{r}\text { HIT-6; } \\
\text { MSQ }\end{array}$ & $\begin{array}{l}\text { OnabotuniumtoxinA was effective towards reduction of headache } \\
\text { frequency and headache-related disability and improvement of } \\
\text { QoL }\end{array}$ \\
\hline $\begin{array}{l}\text { Holroyd } \\
\text { et al. [7] }\end{array}$ & $\begin{array}{l}232 \text { pts with } \\
\text { MA and } \\
\text { MWA }\end{array}$ & $\begin{array}{l}\beta \text {-blocker vs placebo vs } \\
\text { BMM }+ \text { placebo vs } \\
\text { BMM }+\beta \text {-blocker }\end{array}$ & MSQ & $\begin{array}{l}\text { The addition of BMM and } \beta \text {-blocker, but not of BMM or } \beta \text {-blocker } \\
\text { alone, improves optimised migraine care in terms of reduced } \\
\text { headache frequency and improved } \mathrm{QoL}\end{array}$ \\
\hline $\begin{array}{l}\text { Smith } \\
\text { et al. } \\
{[15]}\end{array}$ & $\begin{array}{l}284 \text { pts with } \\
\text { migraine }\end{array}$ & Participation to MMMP & $\begin{array}{r}\text { HIT-6; } \\
\text { MSQ }\end{array}$ & $\begin{array}{l}\text { Patients participating to MMMP reported reduction of headache } \\
\text { frequency and disability, improvement in cognitive and emotional } \\
\text { aspects of headache management and QoL }\end{array}$ \\
\hline $\begin{array}{l}\text { Beran and } \\
\text { Spira [6] }\end{array}$ & $\begin{array}{l}96 \text { pts with } \\
\text { CHD }\end{array}$ & Levetiracetam vs placebo & SF-36 & $\begin{array}{l}\text { No significant reduction of headache frequency is shown; only } \\
\text { mental health aspect of QoL is significantly improved }\end{array}$ \\
\hline $\begin{array}{l}\text { Guyuron } \\
\text { et al. [9] }\end{array}$ & $\begin{array}{l}69 \text { pts with } \\
\text { MA and } \\
\text { MWA }\end{array}$ & $\begin{array}{l}\text { Surgical deactivation of trigger } \\
\text { sites }\end{array}$ & $\begin{array}{l}\text { MIDAS; } \\
\text { MSQ; } \\
\text { SF-36 }\end{array}$ & $\begin{array}{l}5 \text { years after surgery, patients showed reduced headache frequency, } \\
\text { reduced disability and improved QoL }\end{array}$ \\
\hline $\begin{array}{l}\text { Novack } \\
\text { et al. } \\
\text { [12] }\end{array}$ & $\begin{array}{l}29 \text { obese pts } \\
\text { with } \\
\text { migraine }\end{array}$ & Bariatric surgery & $\begin{array}{l}\text { HIT-6; } \\
\text { MIDAS }\end{array}$ & $\begin{array}{l}6 \text { months after surgery, frequency of headache and headache-related } \\
\text { disability were significantly reduced }\end{array}$ \\
\hline $\begin{array}{l}\text { Raggi } \\
\text { et al. } \\
\text { [13] }\end{array}$ & $\begin{array}{l}87 \text { pts with } \\
\text { MA and } \\
\text { MWA }\end{array}$ & Standard treatment & $\begin{array}{l}\text { SF-36; } \\
\text { WHO- } \\
\text { DAS-2 }\end{array}$ & $\begin{array}{l}\text { Changes over } 3 \text { months, in a sample of patients currently under } \\
\text { treatment, in disability and QoL were small or negligible }\end{array}$ \\
\hline $\begin{array}{l}\text { Voigt } \\
\text { et al. } \\
{[16]}\end{array}$ & $\begin{array}{l}42 \text { pts with } \\
\text { MA and } \\
\text { MWA }\end{array}$ & OMT group vs control group & $\begin{array}{l}\text { SF-36; } \\
\text { MIDAS }\end{array}$ & $\begin{array}{l}\text { Although number of days with migraine was not significantly } \\
\text { reduced over } 6 \text { months, there was a reduction in patients' } \\
\text { disability and improvement in QoL }\end{array}$ \\
\hline $\begin{array}{l}\text { Faber } \\
\text { et al. } \\
{[10]}\end{array}$ & $\begin{array}{l}89 \text { pts with } \\
\text { MA and } \\
\text { MWA }\end{array}$ & $\begin{array}{l}\text { Surgical deactivation of trigger } \\
\text { sites }\end{array}$ & $\begin{array}{l}\text { MIDAS; } \\
\text { MSQ }\end{array}$ & $\begin{array}{l}5 \text { years after surgery, patients showed reduced headache frequency, } \\
\text { reduced disability and improved QoL, which are accompanied by } \\
\text { a relevant cost saving }\end{array}$ \\
\hline $\begin{array}{l}\text { Raggi } \\
\text { et al. [2] }\end{array}$ & $\begin{array}{l}102 \text { pts with } \\
\text { MA and } \\
\text { MWA }\end{array}$ & Standard treatment & $\begin{array}{l}\text { SF-36; } \\
\text { WHO- } \\
\text { DAS-2 }\end{array}$ & $\begin{array}{l}\text { Headache frequency and severity was stable over } 3 \text { months, but } \\
\text { small improvement in disability was observed }\end{array}$ \\
\hline $\begin{array}{l}\text { Seng et al. } \\
{[8]}\end{array}$ & $\begin{array}{l}177 \text { pts with } \\
\text { MA and } \\
\text { MWA }\end{array}$ & $\begin{array}{l}\beta \text {-blocker; BMM; BMM + } \beta \text { - } \\
\text { blocker }\end{array}$ & $\begin{array}{l}\text { MSQ; } \\
\text { HDI }\end{array}$ & $\begin{array}{l}\text { Patients with comorbidity of anxiety or mood disorders showed } \\
\text { larger reduction in headache frequency and improvement in QoL } \\
\text { and disability }\end{array}$ \\
\hline $\begin{array}{l}\text { Serra et al. } \\
\text { [11] }\end{array}$ & $\begin{array}{l}30 \text { pts with } \\
\mathrm{CM} \text { and } \\
\mathrm{MOH}\end{array}$ & ONS & $\begin{array}{l}\text { MIDAS; } \\
\text { SF-36 }\end{array}$ & $\begin{array}{l}\text { After } 12 \text { months, patients with ONS device implantation showed a } \\
\text { decreased headache frequency, reduced disability and improved } \\
\text { QoL }\end{array}$ \\
\hline
\end{tabular}

$M A$ migraine with aura; $M W A$ migraine without aura; $C M$ chronic migraine; $C H D$ chronic daily headache; $M O H$ medication overuse headache; $B M M$ behavioural migraine management; $M M M P$ mercy migraine management programme; OMT osteopathic manipulative treatment; ONS occipital nerve stimulation; $Q o L$ quality of life; HIT-6 headache impact test; $M S Q$ migraine specific quality of life questionnaire; $S F-36$ 36-items short-form survey; MIDAS migraine disability assessment; WHO-DAS II WHO disability assessment schedule; HDI headache disability inventory

patient education programme [15] and the second on osteopathic manipulative treatment [16]. Finally, the two trials on $\beta$-blockers also included a behavioural management approach in migraine treatment [7, 8].

The results of these trials showed that headache frequency, patients' HRQoL and disability were positively impacted by preventive treatments with different compounds and surgical approaches as well as by behavioural or educational treatments. These positive outcomes were less evident in two studies: the double-blind, randomised placebo-controlled study on levetiracetam in $\mathrm{CDH}$ by Beran and Spira [6] and the randomized study on osteopathic manipulative treatment of female patients with migraine by Voigt et al. [16], In these reports, however, some changes towards improvement in QoL and in disability were observed. Similar results were found in the two observational studies by Raggi et al. [13, 14] in which small changes in QoL and disability were detected over a three-month follow-up period in samples of patients currently under treatment, although headache frequency was substantially stable.

Our review confirmed that the most commonly used PROMs were three disease-specific tools: the migraine disability assessment (MIDAS) [17] and the headache impact test questionnaire (HIT-6) [18], among those investigating disability and impact on daily activities, and 
the migraine specific quality of life questionnaire (MSQ) [19] among those measuring the effects on HRQoL. In six studies a generic HRQoL tool, the 36-items short-form survey (SF-36) [20], was also used.

\section{Discussion}

This review reported the most recent developments in the field of headache as far as the use of PROMs measuring HRQoL and disability in clinical trials and longitudinal observational studies on headache patients.

Overall, the results of the published reports showed that several interventions aimed to reduce the frequency of headache are likely to have beneficial effects on the level of disability and also of HRQoL. This observation is consistent with the results of a recent literature review [2], focused on migraine, in which the most relevant determinants of improvement over time were the use of diseasespecific treatments, in particular symptomatic and prophylactic medications as well as surgery, and the reduction of headache frequency. On the other hand, a trend towards improvement in patient's health status was evident, even in reports in which the frequency of headache was stable over different study periods-for reasons possibly including low efficacy of treatment as well as the fact of being already in treatment.

Some limitations need to be considered in the interpretation of our results, the most relevant being the limited span of period of the present literature research, and the fact that only PubMed has been searched. Furthermore, most of the papers included in our analyses were clinical trials, in which a strong control over study variables was performed. This approach is likely to reduce the ecological validity of our results, as subjects participating in clinical trials are exposed to a situation that is not the same commonly found in daily practice, where clinicians have to deal also with issues such as acceptance and adherence to treatments [21,22].

\section{Future directions}

The results of this study confirm that some disability and HRQoL tools currently used in clinical research can be viewed as sensitive outcome measures in assessing the changes in the impact of headache disorders in patients under specific treatments, as well as in observational studies out of the setting of a formal clinical trial.

Overall our findings suggest that the personal and societal costs of headache disorders are likely to be reduced when headache patients receive appropriate treatments and when continuity of care is offered.
In terms of future directions, we note that the systematic use of PROMs should be encouraged both in the clinical practice and in the research field. The assessment of disability in different domains and of the limitations in quality of life domains may be particularly relevant when dealing with "difficult headache patients" (i.e. those with chronic headache forms andlor medication overuse) in whom classical endpoints, such as number of headache episodes or of headache days, may be not sufficient to offer a valid insight into longitudinal changes over follow-up periods.

This concepts were in fact included in the "Guidelines for controlled trials of prophylactic treatment of chronic migraine in adults" published in 2008 [23], and in a more detailed way in the recently published "Guidelines for controlled trials of drugs in migraine" proposed by the International Headache Society Clinical Trials Subcommittee [24]. In this paper it is stated that "endpoints currently used in migraine trials may not reflect all participants' values and are not appropriate to assess the global effect of treatments on patient-perceived sense of well-being and quality of performance in different roles and daily activities", and that consequently "The use of standardized, validated tools to assess the changes in ability to function and in HRQOL in clinical trials is recommended as secondary endpoints".

A widespread use of PROMs will also allow a better characterization of the information provided by the different tools in order to address the choice of the most appropriate instruments to be used in a particular clinical and research setting.

Conflict of interest The authors certify that there is no actual or potential conflict of interest in relation to this article.

\section{References}

1. Buse DC, Rupnow MF, Lipton RB (2009) Assessing and managing all aspects of migraine: migraine attacks, migraine-related functional impairment, common comorbidities, and quality of life. Mayo Clin Proc 84:422-435

2. Raggi A, Giovannetti AM, Quintas R, D'Amico D, Cieza A, Sabariego C, Bickenbach JE, Leonardi M (2012) A systematic review of the psychosocial difficulties relevant to patients with migraine. J Headache Pain 13:595-606

3. D’Amico D, Grazzi L, Usai S, Raggi A, Leonardi M, Bussone G (2011) Disability in chronic daily headache: state of the art and future directions. Neurol Sci 32:S71-S76

4. Lantéri-Minet M, Duru G, Mudge M, Cottrell S (2011) Quality of life impairment, disability, and economic burden associated with chronic daily headache, focusing on chronic migraine with or without medication overuse: a systematic review. Cephalalgia 31:837-850

5. Dodick DW, Turkel CC, DeGryse RE, Aurora SK, Silberstein SD, Lipton RB, Diener HC, Brin MF; PREEMPT Chronic Migraine Study Group (2010) OnabotulinumtoxinA for treatment of chronic migraine: pooled results from the double-blind, 
randomized, placebo-controlled phases of the PREEMPT clinical program. Headache 50:921-936

6. Beran RG, Spira PJ (2011) Levetiracetam in chronic daily headache: a double-blind, randomised placebo-controlled study. (The Australian KEPPRA Headache Trial [AUS-KHT]). Cephalalgia 31:530-536

7. Holroyd KA, Cottrell CK, O'Donnell FJ, Cordingley GE, Drew JB, Carlson BW, Himawan L (2010) Effect of preventive (beta blocker) treatment, behavioural migraine management, or their combination on outcomes of optimised acute treatment in frequent migraine: randomised controlled trial. BMJ 341:c4871

8. Seng EK, Holroyd KA (2012) Psychiatric comorbidity and response to preventative therapy in the treatment of severe migraine trial. Cephalalgia 32:390-400

9. Guyuron B, Kriegler JS, Davis J, Amini SB (2011) Five-year outcome of surgical treatment of migraine headaches. Plast Reconstr Surg 127:603-608

10. Faber C, Garcia RM, Davis J, Guyuron B (2012) A socioeconomic analysis of surgical treatment of migraine headaches. Plast Reconstr Surg 129:871-877

11. Serra G, Marchioretto F (2012) Occipital nerve stimulation for chronic migraine: a randomized trial. Pain Physician 15:245-253

12. Novack V, Fuchs L, Lantsberg L, Kama S, Lahoud U, Horev A, Loewenthal N, Ifergane G (2011) Changes in headache frequency in premenopausal obese women with migraine after bariatric surgery: a case series. Cephalalgia 31:1336-1342

13. Raggi A, Leonardi M, Bussone G, D'Amico D (2011) Value and utility of disease-specific and generic instruments for assessing disability in patients with migraine, and their relationships with health-related quality of life. Neurol Sci 32(3):387-392

14. Raggi A, Leonardi M, Bussone G, D’Amico D (2013) A 3-month analysis of disability, quality of life, and disease course in patients with migraine. Headache 53:297-309

15. Smith TR, Nicholson RA, Banks JW (2010) Migraine education improves quality of life in a primary care setting. Headache 50:600-612
16. Voigt K, Liebnitzky J, Burmeister U, Sihvonen-Riemenschneider H, Beck M, Voigt R, Bergmann A (2011) Efficacy of osteopathic manipulative treatment of female patients with migraine: results of a randomized controlled trial. J Altern Complement Med 17:225-230

17. Stewart WF, Lipton RB, Kolodner KB, Sawyer J, Lee C, Liberman JN (2000) Validity of the migraine disability assessment (MIDAS) score in comparison to a diary-based measure in a population sample of migraine sufferers. Pain 88:41-52

18. Kosinski M, Bayliss MS, Bjorner JB, Ware JE Jr, Garber WH, Batenhorst A, Cady R, Dahlöf CG, Dowson A, Tepper S (2003) A six-item short-form survey for measuring headache impact: the HIT-6. Qual Life Res 12:963-974

19. Jhingran P, Osterhaus JT, Miller DW, Lee JT, Kirchdoerfer L (1998) Development and validation of the migraine-specific quality of life questionnaire. Headache 38:295-302

20. Ware JE (2000) SF-36 health survey update. Spine 25:3130-3139

21. Katić BJ, Krause SJ, Tepper SJ, Hu HX, Bigal ME (2010) Adherence to acute migraine medication: what does it mean, why does it matter? Headache 50:117-129

22. D'Amico D, Tepper SJ (2008) Prophylaxis of migraine: general principles and patient acceptance. Neuropsychiatr Dis Treat 4:1155-1167

23. Tfelt-Hansen P, Pascual J, Ramadan N, Dahlöf C, D’Amico D, Diener HC, Hansen JM, Lanteri-Minet M, Loder E, McCrory D, Plancade S, Schwedt T; International Headache Society Clinical Trials Subcommittee (2012) Guidelines for controlled trials of drugs in migraine: $3 \mathrm{rd}$ edn. A guide for investigators. Cephalalgia 32(1):6-38

24. Silberstein S, Tfelt-Hansen P, Dodick DW, Limmroth V, Lipton RB, Pascual J, Wang SJ; Task Force of the International Headache Society Clinical Trials Subcommittee (2008) Guidelines for controlled trials of prophylactic treatment of chronic migraine in adults. Cephalalgia 28(5):484-495 